\title{
CRESCIMENTO DE GENÓTIPOS DE SORGO PLANTADOS NOS SENTIDOS NORTE-SUL E LESTE-OESTE ${ }^{1}$
}

\author{
EDUARDO FERREIRA RODRIGUES ${ }^{2}$ e IZABEL CRISTINA LEITE ${ }^{3}$
}

\begin{abstract}
RESUMO - O objetivo do presente trabalho foi estudar o crescimento de plantas de seis genótipos de sorgo (Sorghum bicolor (L.) Moench), a saber: dois sacarinos, dois graníferos e dois forrageiros, cultivadas com as linhas de plantio orientadas no sentido Norte-Sul e Leste-Oeste. Instalou-se, em setembro de 1994, o ensaio em área experimental da Faculdade de Ciências Agrárias e Veterinárias (FCAVJ) - UNESP, utilizando delineamento em blocos casualizados, com doze tratamentos e três repetições. As avaliações foram feitas mediante amostragens semanais, determinando-se massa seca acumulada, área foliar e distribuição da massa seca nas diferentes partes da planta. Os materiais sacarinos cresceram mais que os graníferos, e os graníferos tiveram ciclo mais curto que os demais. A distribuição de massa seca caracterizou aptidão de cada genótipo, ou seja, alta eficiência na exportação de material para os colmos nos sacarinos, exportação preferencialmente para os grãos nos graníferos, e exportação para colmos e grãos, evidenciando dupla aptidão, nos forrageiros. O padrão de distribuição de massa seca não foi afetado pela orientação das linhas de plantio.
\end{abstract}

Termos para indexação: Sorghum bicolor, massa seca, área foliar.

\section{GROWTH OF SORGHUM GENOTYPES CULTIVATED IN NORTH-SOUTH AND EAST-WEST DIRECTIONS}

\begin{abstract}
The present work studied the growth of six genotypes of sorghum (Sorghum bicolor (L.) Moench): two of sweet sorghum, two of grain sorghum and two of forage sorghum, planted in rows oriented in the North-South and East-West directions. In September, 1994, the trial was conducted on a plot of the Faculdade de Ciências Agrárias e Veterinárias de Jaboticabal (FACVJ) of the UNESP, utilizing a randomized block design with twelve treatments and three replicates. The evaluations were made by means of weekly samplings, determining dry matter accumulation, leaf area and distribution of dry matter in the different plant parts. The sweet sorghum grew faster than the grain sorghum, and the grain sorghum had a shorter cycle than the others. The distribution of dry matter characterized the aptidude of each genotype, i.e., high efficiency in the transport of dry matter to the culms in the sweet sorghums, and preferential transport to grains in grain sorghum, and showing double aptitude in transport to the culms ands grains in the forage sorghums. The distribution pattern of dry matter was not affected by the orientation of planting rows.
\end{abstract}

Index terms: Sorghum bicolor, dry matter, leaf area.

\section{INTRODUÇÃO}

A possibilidade de cometer erros durante uma avaliação inicial de genótipos, principalmente nos programas de melhoramento, é grande, na medida

\footnotetext{
${ }^{1}$ Aceito para publicação em 5 de maio de 1998.

${ }^{2}$ Eng. Agr., M.Sc., UEMA, Campus Universitário Cidade Paulo VI, Dep. Quimbi, Tirirical, CEP 65150-900 São Luís, MA.

${ }^{3}$ Eng ${ }^{\mathrm{a}}$ Agr ${ }^{\mathrm{a}}$, Dr ${ }^{\mathrm{a}}$., Dep. de Biologia Aplicada à Agropecuária, UNESP, Câmpus de Jaboticabal, Rodovia Carlos Tonanni, $\mathrm{Km}$ 5, CEP 14870-000 Jaboticabal, SP. E-mail: isabelcl@fcavj.unesp.br
}

em que apenas aspectos produtivos são levados em consideração. É necessário que um genótipo bem adaptado possua plasticidade frente às diversas influências ambientais e práticas culturais que interferem no processo produtivo.

Com o emprego da técnica da análise de crescimento, a qual baseia-se em aspectos fisiológicos e anatômicos da folha como os principais fatores do crescimento, e tendo em vista que suas funções são extremamente vitais, é possível aferir processos fisiológicos, dentre eles a fotossíntese líquida.

A atividade fotossintética é um processo amplo que envolve numerosos passos importantes e 
interrelacionados. Todos os processos dependem das condições ambientais, porém cada um deles obedece a diferentes leis (Benincasa, 1977).

A radiação solar tem sido estudada principalmente por sua influência sobre a fotossíntese, enfatizando-se os efeitos que as modificações da intensidade luminosa podem causar (Benincasa, 1977). Com este objetivo, Blackman \& Wilson (1951) usaram diferentes tipos de telas para promover atenuações da radiação solar total sobre diferentes espécies vegetais, em casa de vegetação. Verificaram uma estreita correlação entre alguns parâmetros de crescimento (razão entre peso de massa seca da parte aérea e da raiz) e a intensidade de luz. Aumento de luz promoveu o crescimento de todas as espécies estudadas. Loomis \& Willians (1969) consideraram que a distribuição da luz dentro da cultura é mais importante do que sua intensidade sobre a cultura. Argumentaram que as folhas totalmente expostas absorvem de 80 a $90 \%$ de radiação incidente na região dos $400-700 \mathrm{~nm}$, e ao meio-dia as folhas superiores absorvem acima da quantidade de luz requerida para a saturação. Desse modo, grande proporção de energia luminosa pode ser dissipada sem contribuir para ganhos na fotossíntese.

A taxa de produção de matéria seca do dossel de uma cultura depende essencialmente da quantidade de energia luminosa absorvida por seus componentes, e de sua eficiência fotossintética. Esta eficiência é afetada pela forma da resposta da taxa fotossintética quando da mudança da densidade de fluxo luminoso (Foale et al., 1984); se um dossel possui resposta curvilínea da lâmina foliar, a eficiência fotossintética do dossel aumentará, caso a energia radiante incidente seja distribuída sobre uma área maior de superfície fotossintetizante, em intensidades menores por unidade de área.

As diferentes disposições das linhas de cultivo em relação ao movimento relativo do sol resultam em maior ou menor interceptação da radiação solar pelas plantas (Denmead et al., 1962).

Este trabalho foi desenvolvido com o objetivo de avaliar a influência da distribuição das plantas de diferentes genótipos de sorgo cultivados em linhas de plantio orientadas no sentido Norte-Sul e LesteOeste, sobre o desenvolvimento da área foliar e so- bre o acúmulo e distribuição de massa seca, e verificar as possíveis diferenças entre os genótipos.

\section{MATERIAL E MÉTODOS}

O presente experimento foi desenvolvido em área da FACV-UNESP, câmpus de Jaboticabal, com coordenadas geográficas de $21^{\circ} 15^{\prime} 22^{\prime \prime} \mathrm{S}$, longitude $48^{\circ} 18^{\prime} 58^{\prime \prime} \mathrm{W}$ e altitude de 595 metros. O clima da área é do tipo Cwa, segundo a classificação de Köppen, que é caracterizado como subtropical temperado, com temperatura média anual próxima de $21^{\circ} \mathrm{C}$ e pluviosidade média anual de $1.311 \mathrm{~mm}$. Foi instalado um experimento no dia $21 \mathrm{de}$ setembro de 1994, utilizando-se um delineamento em blocos casualizados, com doze tratamentos e três repetições; os tratamentos foram distribuídos em um esquema fatorial $6 \times 2$; seis genótipos de sorgo foram submetidos a duas diferentes formas de plantio: linhas plantadas com orientação Leste-Oeste, e linhas plantadas com orientação Norte-Sul. O tamanho das parcelas era de 5,0 x 6,0 m.

$\mathrm{Na}$ análise de crescimento, observou-se o desenvolvimento da área foliar ao longo do ciclo, e o acúmulo de massa seca. Para a determinação da área foliar, em cada amostragem foram separadas dez lâminas foliares por parcela, medindo o comprimento (C) e a maior largura (L) de cada lâmina. Em seguida, acondicionaram-se essas lâminas, separadamente das lâminas restantes, em sacos de papel devidamente identificados, secadas em estufa de aeração forçada, marca FANEN. A partir do peso da massa seca das lâminas medidas, da sua área - estimada pelo produto $\mathrm{C} \times \mathrm{L} \times \mathrm{Fc}-\mathrm{e}$ da massa seca total das lâminas restantes, estimou-se, por regra de três simples, a área foliar total das plantas amostradas. $\mathrm{O}$ fator de correção $(\mathrm{Fc})$ usado foi de 0,68 . Para a determinação da massa seca, procedeu-se ao mesmo método para as lâminas foliares; as diferentes partes de cada planta (bainhas, colmos, inflorescências e lâminas senescentes) foram separadas em sacos de papel devidamente identificados.

\section{RESULTADOS E DISCUSSÃO}

\section{Área foliar}

A área foliar é um parâmetro fundamental em uma planta e a análise do seu comportamento em face de um estímulo ambiental é, dentre outros fatores, imprescindível, pois as respostas obtidas de crescimento são uma conseqüência da área foliar. Materiais mais produtivos, possuem uma melhor adequação em ter- 
mos de manter a área foliar por um período mais prolongado.

Nota-se, pela Fig. 1, que os sorgos sacarinos BR-501 e BR-506 são variedades que possuem boa capacidade de desenvolver a área foliar até por volta dos 96 dias após o plantio, com valor máximo em torno dos $500 \mathrm{dm}^{2}$; no tratamento Norte-Sul, observa-se ligeira vantagem no que se refere à manutenção da área foliar por um período mais prolongado. Nos graníferos, CS-111 e CS-822, é mais evidente essa vantagem. Pode-se apontar o melhor desempenho do híbrido CS-822, que permanece com área foliar maior e mais estável (maior duração da área foliar útil) em ambos os tratamentos (Fig. 2). Assim como no caso dos sacarinos (Fig. 1), um comportamento semelhante é observado quanto aos tipos forrageiros CS-SILO e CS-SILO 03. Já o tratamento Norte-Sul apresenta valores maiores de área foliar em relação ao Leste-Oeste (Fig. 3). O híbrido
CS-SILO 03 é de melhor desempenho nos dois tratamentos.

Sob este aspecto, a eficiência em fazer fotossíntese é objeto de estudo dos melhoristas, pois quando a planta permanece por um período maior produzindo assimilados, esta é uma característica que pode ser manejada ou explorada na condução dos programas de melhoramento. Ressalta-se a existência de uma relação inversa quando a área foliar interfere na produtividade biológica em razão do autosombreamento (Melges et al., 1989), pois há uma relação inversa entre área foliar e taxa de acúmulo de massa seca.

\section{Acúmulo e distribuição da massa seca}

$\mathrm{Na}$ Fig. 4, constata-se que na orientação LesteOeste, a cultivar BR-506 foi a que apresentou, no final do período, a maior massa seca. Na orientação
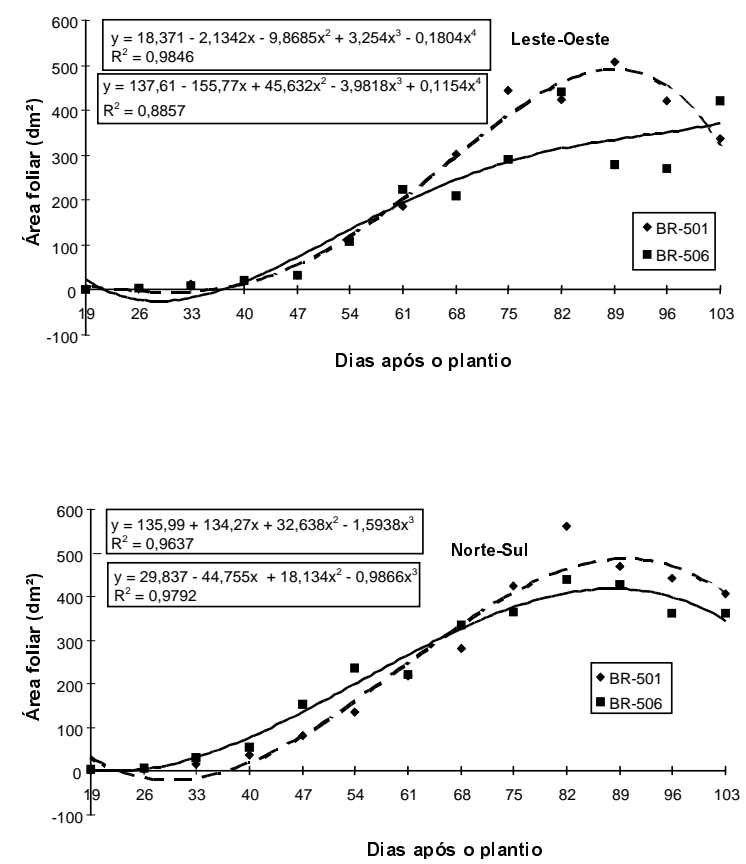

FIG. 1. Área foliar apresentada por plantas de sorgo sacarino (Sorghum bicolor (L.) Moench), cultivadas em linhas de plantio orientadas no sentido Leste-Oeste e Norte-Sul.
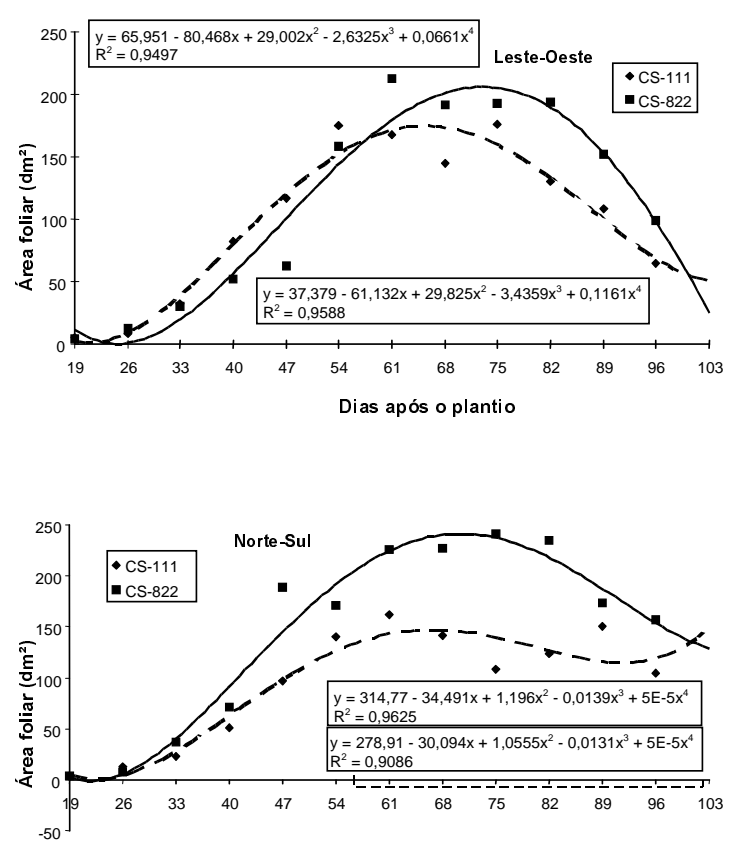

Dias após o plantio

FIG. 2. Área foliar apresentada por plantas de sorgo granífero (Sorghum bicolor (L.) Moench), cultivadas em linhas de plantio orientadas no sentido Leste-Oeste e Norte-Sul. 

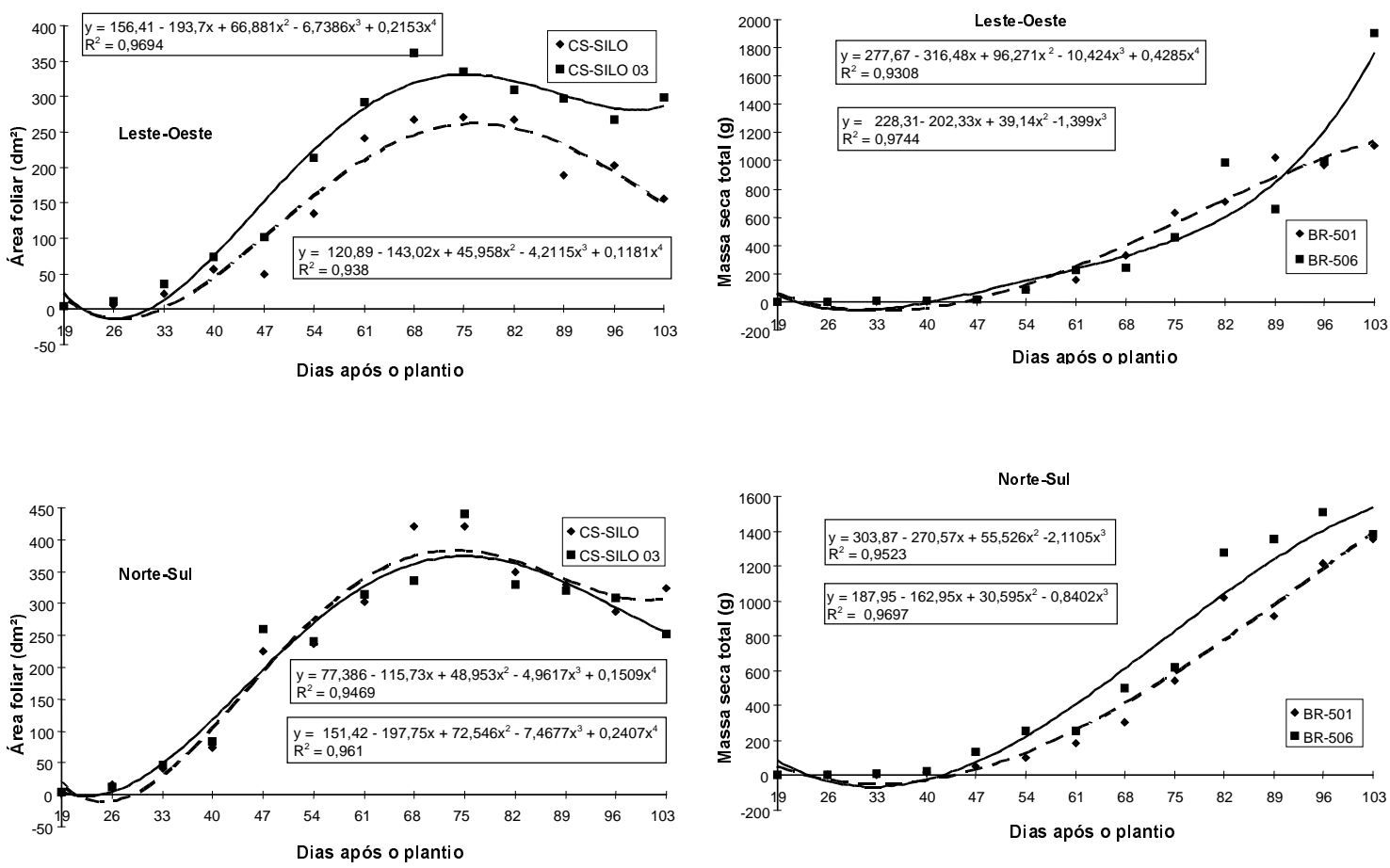

FIG. 3. Área foliar apresentada por plantas de sorgo forrageiro (Sorghum bicolor (L.) Moench), cultivadas em linhas de plantio orientadas no sentido Leste-Oeste e Norte-Sul.

Norte-Sul, a BR-506 revelou-se superior muito antes (até 47 dias após o plantio), mas as diferenças foram menores no tocante ao acúmulo de massa seca, e pela curva de tendência percebe-se que não continuará aumentando a massa seca, ao passo que no tratamento anterior (Leste-Oeste), não há evidências de estabilização da massa seca. A BR-506 foi, portanto, mais afetada pela orientação das linhas de plantio do que a BR-501. No que se refere ao padrão de distribuição (Fig. 5 e 6), observa-se que os colmos funcionaram como drenos prioritários, uma vez que constituíam, ao final do período, a maior parte da massa seca das plantas. Constata-se, também, que a cultivar BR-506 demonstrou-se ligeiramente mais eficiente que a BR-501 no processo de translocação de material das folhas para os colmos. Observa-se, ainda, que não houve efeito da orientação das linhas

de plantio sobre o padrão de distribuição da massa seca.

Quanto aos híbridos de sorgo granífero (CS-111 e CS-822), cujos dados estão representados na Fig 7, nota-se que a massa seca atingiu um pico de acúmulo por volta dos 82 dias após o plantio. O CS-822 apresentou os maiores valores de massa seca, embora, no final do período, as diferenças tenham sido pequenas. No tratamento com as linhas de plantio orientadas no sentido Leste-Oeste, o CS-822 só superou o CS-111 no final do período (a partir dos 82 dias após o plantio). Analisando-se os padrões de acúmulo de massa seca (Figs. 8 e 9), notase que são as inflorescências que funcionam como drenos eficientes e representam, ao final do período, a maior fração da massa seca acumulada pelas plantas, caracterizando-os como materiais 

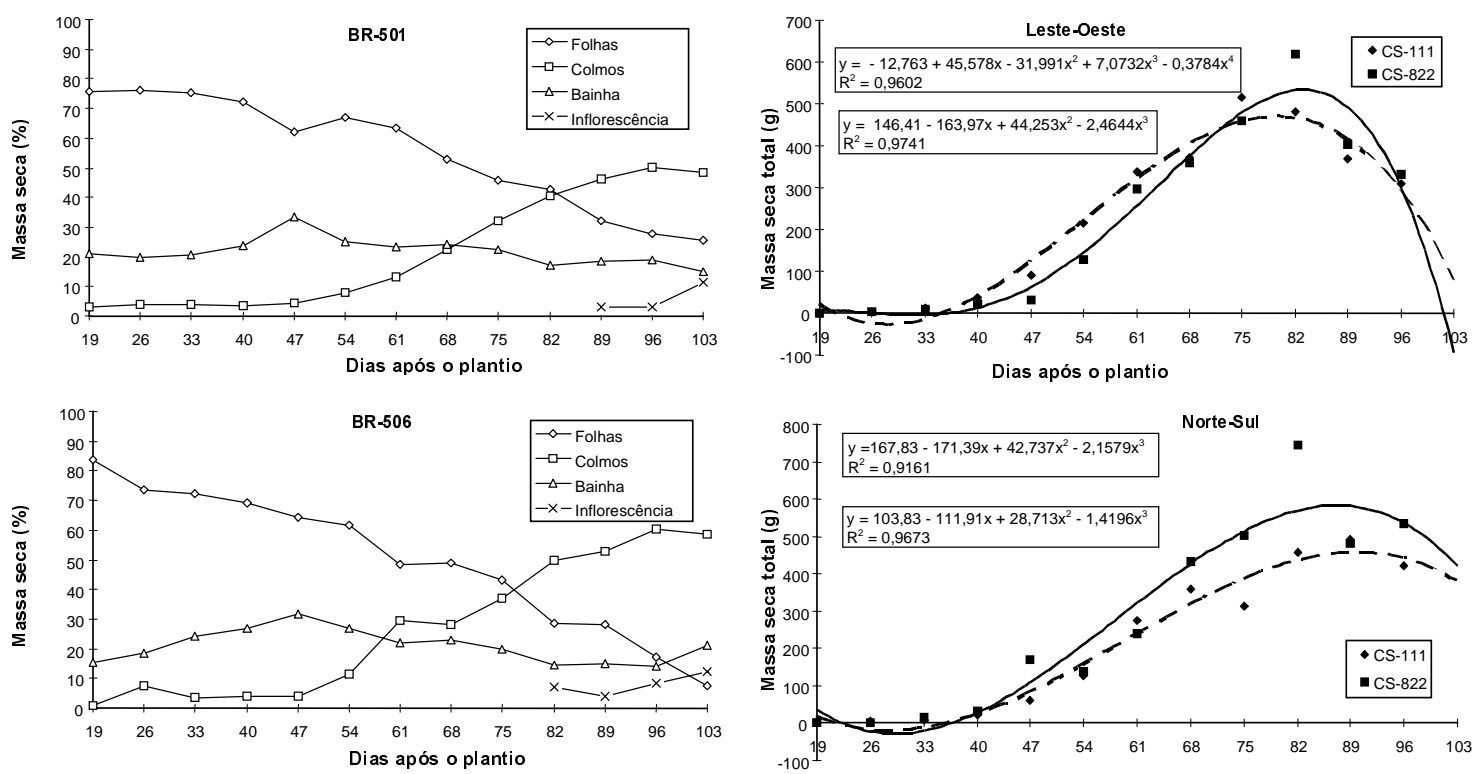

FIG. 5. Massa seca, em porcentagem do total, apresentada pelas diferentes partes de plantas de sorgo sacarino (Sorghum bicolor (L.) Moench), cultivadas em linhas de plantio orientadas no sentido Leste-Oeste.
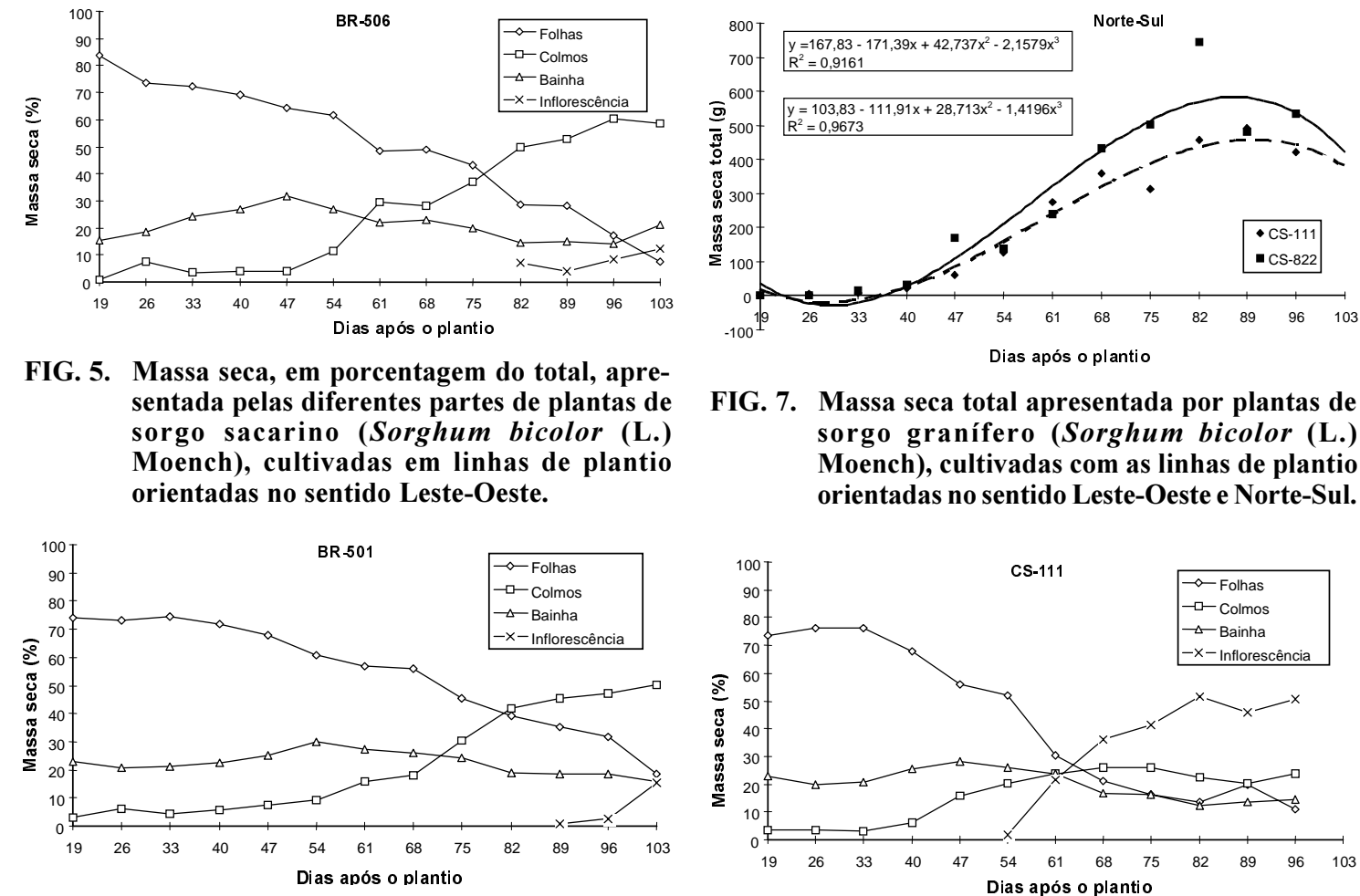

FIG. 7. Massa seca total apresentada por plantas de sorgo granífero (Sorghum bicolor (L.) Moench), cultivadas com as linhas de plantio orientadas no sentido Leste-Oeste e Norte-Sul.
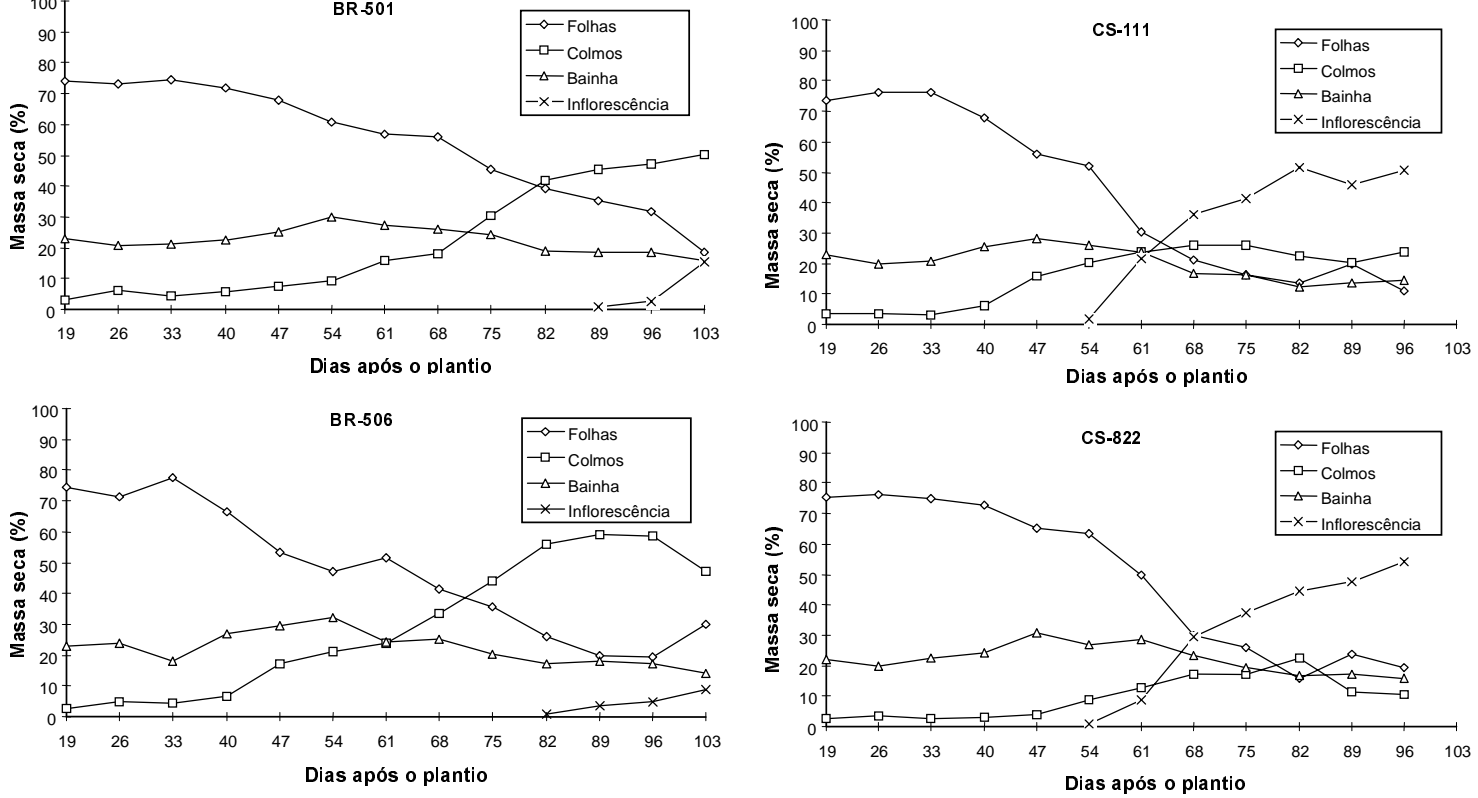

FIG. 6. Massa seca, em porcentagem do total, apresentada pelas diferentes partes de plantas de sorgo sacarino (Sorghum bicolor (L.) Moench), cultivadas em linhas de plantio orientadas no sentido Norte-Sul.

FIG. 8. Massa seca, em porcentagem do total, apresentada pelas diferentes partes de plantas de sorgo granífero (Sorghum bicolor (L.) Moench), cultivadas em linhas de plantio orientadas no sentido Leste-Oeste. 
graníferos. Comparando-se os dois híbridos, verifica-se que o padrão de distribuição da massa seca entre as diferentes partes das plantas é semelhante, e que, também nesse caso, não houve efeito da orientação das linhas de plantio.

Na Fig. 10, são mostrados os valores da massa seca referentes aos materiais forrageiros, e nas Figs. 11 e 12 o padrão de distribuição da massa seca.

Com as linhas de plantio orientadas no sentido Leste-Oeste, as diferenças foram mais evidentes, sendo o CS-SILO 03 consideravelmente superior ao CSSILO. Já no tratamento Norte-Sul, as diferenças não foram tão evidentes, devido ao melhor comportamento do CS-SILO. No entanto, os padrões de distribuição destes materiais são semelhantes aos dos genótipos sacarinos, e pode-se observar uma porcentagem maior para os colmos (em torno de 70\%) e para as inflorescências, possuindo uma participação de aproximadamente $30 \%$ da massa seca ao final do período, o que demonstra que estes materiais apresentam características de dupla aptidão, tanto
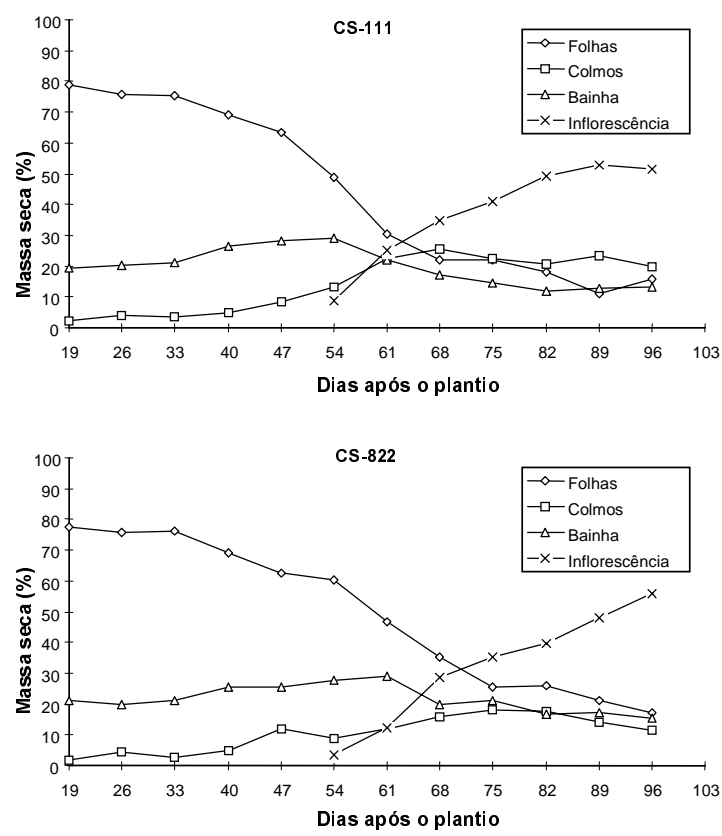

FIG. 9. Massa seca, em porcentagem do total, apresentada pelas diferentes partes de plantas de sorgo granífero (Sorghum bicolor (L.) Moench), cultivadas em linhas de plantio orientadas no sentido Norte-Sul.
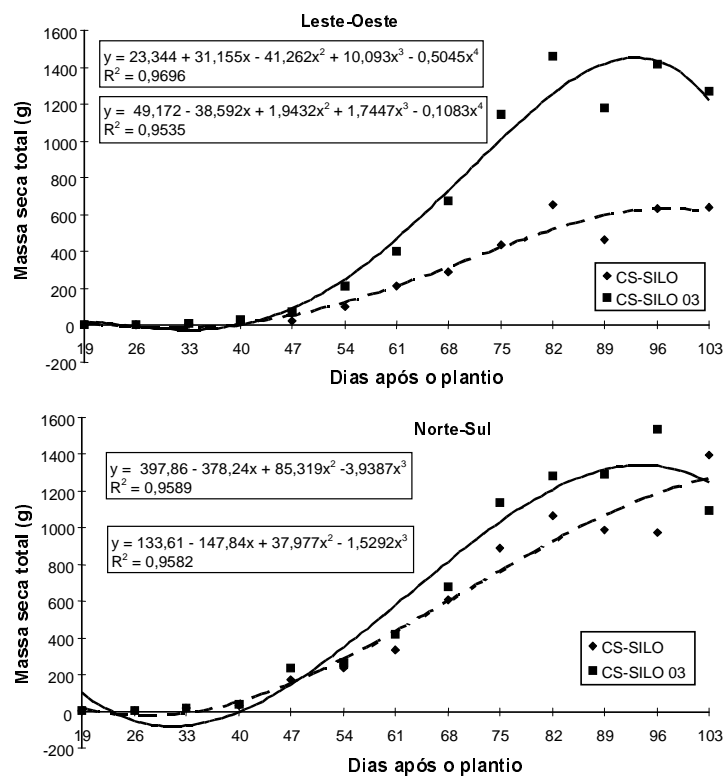

FIG. 10. Massa seca total apresentada por plantas de sorgo forrageiro (Sorghum bicolor (L.) Moench), cultivadas com as linhas de plantio orientadas no sentido Leste-Oeste e Norte-Sul.
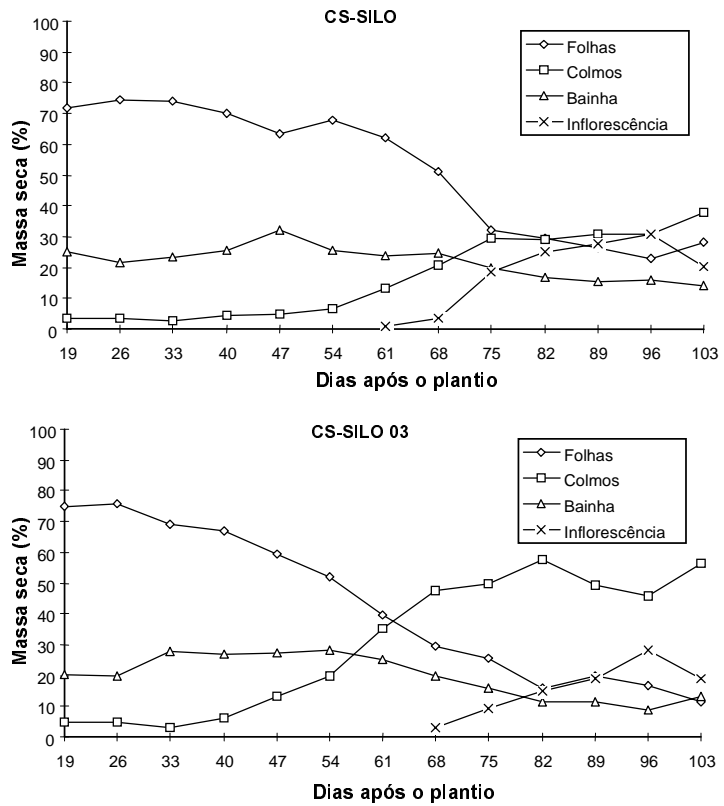

FIG. 11. Massa seca, em porcentagem do total, apresentada pelas diferentes partes de plantas de sorgo forrageiro (Sorghum bicolor (L.) Moench), cultivadas em linhas de plantio orientadas no sentido Leste-Oeste. 

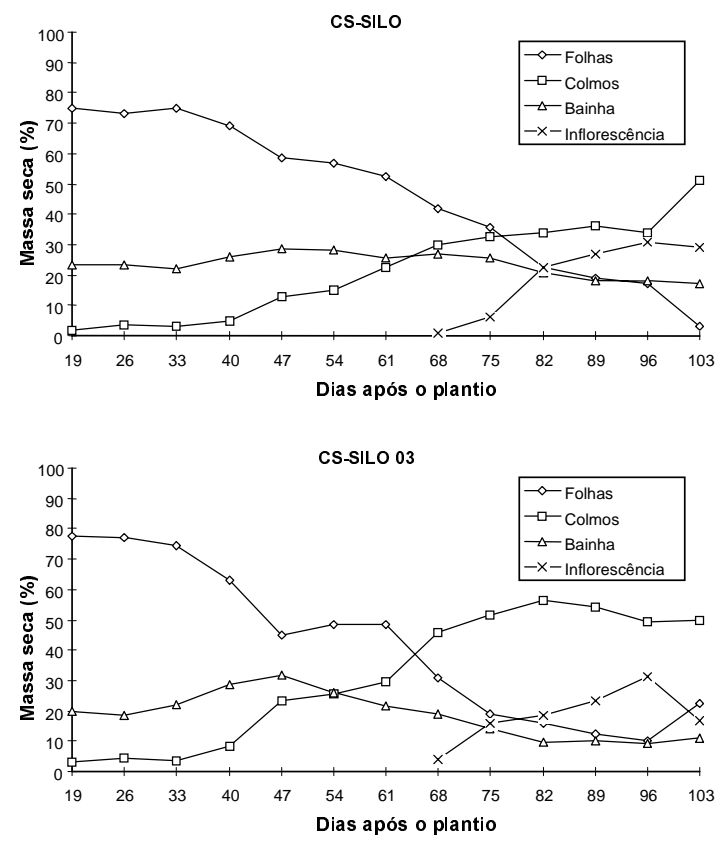

FIG. 12. Massa seca, em porcentagem do total, apresentada pelas diferentes partes de plantas de sorgo forrageiro (Sorghum bicolor (L.) Moench), cultivadas em linhas de plantio orientadas no sentido Norte-Sul.

no tocante aos colmos como no que diz respeito às inflorescências.

\section{CONCLUSÕES}

1. Os genótipos sacarinos (BR-501 e BR-506) crescem muito mais que os graníferos (CS-111 e CS-822), e os graníferos apresentam um ciclo mais curto que os demais.

2. Na cultivar BR-506 de sorgo sacarino, a massa seca acumulada é superior na orientação Leste-Oeste das linhas de plantio.

3. Há um melhor comportamento do híbrido CS-SILO, de sorgo forrageiro, com as linhas de plantio orientadas no sentido Norte-Sul.
4. A distribuição da massa seca caracteriza claramente o propósito com que são utilizados os diferentes genótipos estudados.

5. A orientação das linhas de plantio não modifica o padrão de distribuição da massa seca dos genótipos de sorgo.

\section{REFERÊNCIAS}

BENINCASA, M.M.P. Influência de exposições Norte e Sul sobre parâmetros de crescimento de Sorghum bicolor (L.) Moench. Jaboticabal: UNESP, Faculdade de Ciências Agrárias e Veterinárias, 1977. 149p. Tese de Livre-Docência.

BLACKMAN, G.E.; WILSON, G.L. Physiological and ecological studies in the analysis of plant environment. VII. An analysis of the different effects of light intensity on the net assimilation rate, leaf-area ratio, and relative growth rate of different species. Annals of Botany, v.15, n.59, p.373-409, 1951.

DENMEAD, L.; FRITSCHEN, L.H.; SHANW, R.H. Spatial distribution of net radiation in a corn field. Agronomy Horticultural, v.54, p.505-510, 1962.

FOALE, M.A.; WILSON, G.L.; COATES, D.B.; HAYDOCK, K.P. Growth and productivity of irrigated Sorghum bicolor (L.) Moench, in Northern Australia. II. Low solar altitude as a possible seasonal constraint to productivity in the tropical dry season. Australian Journal of Agricultural Research, v.35, p.229-238, 1984.

LOOMIS, R.S.; WILLIANS, W.A. Productivity and the morfology of crop stands: patterns with leaves. In: DINAUER, R.C. (Ed.). Physiological aspects of crop yield. Madison: ASA/CSSA, 1969. p.27-47.

MELGES, E.; LOPES, N.F.; OLIVA, M.A. Crescimento e conversão da energia solar, em soja cultivada sob quatro níveis de radiação solar. Pesquisa Agropecuária Brasileira, Brasília, v.24, n.9, p.1065-1072, 1989. 